\title{
Significance of bacterial and viral genotypes as a risk factor in driving cancer (Review)
}

\author{
DIWASH JANGAM $^{1}$, ALEXANDRA BUTZMANN ${ }^{2}$, KAUSHIK SRIDHAR $^{2}$, STANLEY DERESINSKI $^{1}$, \\ NIAZ BANAEI $^{1}$ and ROBERT SHIGEO OHGAMI ${ }^{2}$ \\ ${ }^{1}$ Department of Pathology, Stanford University, Stanford, CA 94305; ${ }^{2}$ Department of Pathology, \\ University of California San Francisco, San Francisco, CA 94143, USA
}

Received Seprember 10, 2019; Accepted January 8, 2020

DOI: $10.3892 / \mathrm{mco} .2020 .2043$

\begin{abstract}
Microbes have been known to drive human cancers for over half a century. However, despite the association of bacterial and viral infections with a high risk of cancer, most infections do not result in the development of cancer. Additionally, certain bacteria and viruses, considered to drive oncogenesis, are commonly prevalent in the global population. The current study performed a comprehensive meta-analysis of primary literature data to identify particular aspects of microbial genotypes as crucial factors that dictate the cancer risks associated with infection. The results indicated the importance of incorporating microbial genotype information with human genotypes into clinical assays for the more efficient diagnosis and prognosis of patients with cancer. The current review focuses on the importance of microbial genotypes and specific genes and genetic differences that are important to human oncogenesis.
\end{abstract}

Correspondence to: Dr Robert Shigeo Ohgami, Department of Pathology, University of California San Francisco, 513 Parnassus Avenue, Room HSW450, UCSF Campus Box 0502, San Francisco, CA 94143, USA

E-mail: robert.ohgami@ucsf.edu

Abbreviations: CMV, cytomegalovirus; CRC, colorectal cancer; IBC, inflammatory breast cancer; HPV, human papilloma virus; HTLV-1, human T-cell leukemia virus-1; HHV8, human herpes virus 8; EBV, epstein barr virus; HAM/TSP, HTLV-1 associated myelopathy/tropical spastic paraparesis; GC, gastric cancer; CagA, cytotoxin-associated gene A; babA2, blood group antigen binding adhesion; DU, duodenal ulcers; OipA, outer inflammatory protein; dupA, duodenal ulcer promoting gene A; FlaA, flagellin A; NPC, nasopharyngeal carcinoma; Cao CTAR2, Cao C-terminal activation region 2; AIDS-KS, AIDS-associated Kaposi's sarcoma; OR, odds ratio; $\mathrm{CI}$, confidence interval; $\mathrm{HCC}$, hepatocellular carcinoma; $\mathrm{HCV}$, hepatitis C virus; UTR, untranslated region; HBV, hepatitis B virus; HCMV, human cytomegalovirus; CRC, colorectal cancer; DFS, disease-free survival; HR, hazards ratio; IBC, inflammatory breast cancer; IL-1 $\beta$, interleukin-1 $\beta$; IL-1RN, IL-1 receptor antagonist; HLA, human leukocyte antigen

Key words: bacteria, virus, genotype, human cancer, risk factor

\section{Contents}

1. Introduction

2. Literature search

3. H. pylori genotypes and cancer risks

4. Viral genotypes and cancer risks

5 Interaction between human and microbe genetic factors

6. Conclusion and prospects

\section{Introduction}

Numerous studies have shown that microbes have the ability to drive the development of cancer (1). A wide variety of microorganisms including viruses (2), and bacteria (3) have been robustly associated with higher risk of cancer. Microbes such as Helicobacter pylori (H. pylori) have been shown to significantly increase the risk of developing gastric cancer and duodenal cancer (4); cytomegalovirus (CMV) associated with subtypes of colorectal cancer (CRC) (5) and inflammatory breast cancer (IBC) (6); human papilloma virus (HPV) infection is associated with many cervical cancers, penile cancers, anogenital, and head and neck cancers (7); human T-cell leukemia virus-1 (HTLV-1) is the oncogenic cause of Adult T cell leukemia (8); human herpes virus 8 (HHV8) infection is associated with subtypes of Castleman disease as well as sarcomas $(9,10)$; and Epstein Barr virus (EBV) is associated with lymphomas derived from B-cells, NK-cells, T-cells, and carcinomas derived from epithelial cells $(11,12)$. Though many cancers are known to be driven by or associated with microbial infections, it should be noted that only a fraction of these infections actually leads to cancer. Only $3 \%$ of $\mathrm{H}$. pylori infections result in gastric cancer (13), approximately $1.5 \%$ of EBV infections are associated with cancer worldwide (11), 5\% of HTLV-1 infected patients develop HTLV-1 associated myelopathy/tropical spastic paraparesis (HAM/TSP) (14). Furthermore, it is interesting that microbes that have been linked with high risk of cancer have a high level of endemic infection. EBV is prevalent in $\sim 90 \%$ of the world's population (15), CMV have frequency of infection ranging from 50 to $100 \%$ in the general adult population worldwide (16), and H. pylori colonizes approximately $50 \%$ of world population (4). Thus, it is evident that other factors, in addition to infection by 
a microorganism of a particular species, must be significant in modifying risks associated with cancer. Factors such as patient genetic background (14), environmental factors (17), status of the immune system (18), and microbial genotype (19) have been known to play important roles in determining cancer risk factors in the presence of microbial infection. Therefore, it is difficult to predict the risk of cancer imposed by microorganisms solely based on their occurrence in an individual. In this review we focus on the importance of microbial genotypes in determining cancer risk factors (Fig. 1; Table I), and discuss the importance of incorporation of this information into clinical diagnosis and prognosis.

\section{Literature search}

Articles with information associated with microbial genotype contributing to the cancer risk were researched in electronic databases. Thirty-two hundred articles resulted from our initial search. From this list, articles that showed relevance to our topic of interest based on their title and published between 1995 and May of 2019 were selected. This resulted in 327 articles. Further, articles that were not published in English, did not have full text available, focused on non-human organisms and cell lines, did not have clear connection between microbial genotype and human cancer, and contained very small sample size without robust statistical support were excluded from our study. Four articles that contained information of interest and were not in our list were added manually. Our final list consisted of 45 articles that were used in our study.

\section{H. pylori genotypes and cancer risks}

Numerous studies have shown that among many genotypes of microbes, some variants are associated with a higher risk of cancer than others. In $H$. pylori, the presence of the Cag pathogenicity island (Cag PAI), a $40 \mathrm{~kb}$ insertion with 27-31 genes flanked by $31 \mathrm{bp}$ direct repeats, is associated with a high risk of gastric cancer (GC) (4). More specifically, a gene called Cytotoxin-associated gene $\mathrm{A}(\operatorname{Cag} A)$ within the Cag PAI is associated with increased risk of gastric cancer and premalignant lesions (20). CagA contains an EPIYA motif, and variation in this motif is associated with differential phosphorylation of CagA which is shown to greatly influence the occurrence of $H$. pylori mediated GC (4). In fact, the odds of developing GC in the presence of one EPIYA segment was increased to seven times compared to CagA negative patients (OR=7.37, 95\% CI: 1.98-27.48) and the presence of two or more EPIYA segments increased the odds to thirty-two-fold higher (OR=32.5, 95\% CI: 8.41-125.58) (21). In addition, all $H$. pylori possess another gene that encodes for a toxin called VacA and variation in its three regions: Signal region (s), middle region (m), and intermediate region (i) have been associated with differential risk of GC induced by $H$. pylori. Specifically, individuals infected with Genotype $\mathrm{s} 1, \mathrm{~m} 1$ and $\mathrm{i} 1$ have a higher risk of $\mathrm{GC}(\mathrm{OR}=5.02,95 \% \mathrm{CI}$ : 2.10-11.98, $\mathrm{P}<0.001)$ and peptic ulcers $(\mathrm{OR}=2.58,95 \% \mathrm{CI}$ : 1.19-5.61, $\mathrm{P}<0.05)$ compared to individuals infected with Genotype s2, $\mathrm{m} 2$ and i2 $(21,22)$. The presence of intact Blood group antigen binding adhesin $(b a b A 2)$ is another factor that has been linked with increased pathogenicity of $H$. pylori. The prevalence of babA2 positive $H$. pylori strains were found to be significantly higher in duodenal ulcers (DU) $(\mathrm{P}=0.0002$, chi squared test) and gastric adenocarcinomas $(\mathrm{P}=0.033$, Chi-squared test); interestingly, the risk factor for $b a b A 2$ increases even more when it is found together with $\operatorname{Cag} A$ and VacA s1 strains (23). Outer inflammatory protein (OipA) is another factor that is known to increase the pathogenicity of H. pylori. OipA is either found in an intact form or an out of frame form; the presence of intact OipA has been reported to increase the risk of DU and was the most robust discrimination factor for separating outcomes of DU and gastritis $(\mathrm{OR}=5$, 95\% CI: 2.1-11.9) (24). Interestingly it has been also reported that the intact form OipA is often linked to more pathogenic determinants of $H$. pylori such as vacAs1, vacAm1, babA2 and most strongly with $\mathrm{CagA}$ positive genotypes. The authors speculate that there is selection for the linkage observed between $\operatorname{cagA}$ and in frame $\operatorname{OipA}$, which is supported by the observation that bacteria harboring cagA colonize poorly when oipA is mutated. Such selective forces may be responsible for sustaining more virulent forms of $H$. pylori. The presence of Duodenal ulcer promoting gene a (dupA) gene in the genome of $H$. pylori has been also associated with increased risk of DU worldwide $(\mathrm{OR}=1.4,95 \% \mathrm{CI}$ : $1.1-1.7, \mathrm{P}=0.001)$ and in addition has also been shown to have increased risk of gastric ulcer and GC in various parts of the world, although dupA seems to promote DU and GC only in certain population worldwide (4,25). Furthermore, an $H$.pylori strain containing a point mutation in a gene encoding a flagella subunit called Flagellin A (FlaA) was shown to decrease the virulence of $H$. pylori, which the authors speculate might be due to its decreased motility as a result of the mutation (26).

\section{Viral genotypes and cancer risks}

Epstein Barr virus. Nasopharyngeal carcinoma (NPC) has a high local control probability after treatment by primary radiotherapy. Despite the prevalence of successful treatment, $\sim 19-29 \%$ of patients develop distant metastases with controlled locoregional disease, and variations in the LMPl gene in EBV have been linked to distant metastasis of NPC (27). A study involving 249 Taiwanese patients was conducted to test if a variation in $L M P 1$, called Cao C-terminal activation region 2 (Cao CTAR2), was associated with the distant metastasis in patients with NPC treated with radiation or chemotherapy. It was observed that patients with tumor harboring the Cao-CTAR2 variant had twice the risk of developing distant metastasis $(\mathrm{HR}=2.01, \mathrm{P}=0.026)$ and a lower overall survival probability $(\mathrm{P}=0.047)$ compared to patients without Cao-CTAR2. The authors also discovered that Cao-CTAR2 had prognostic significance that was independent of patient clinical characteristics and conveyed that this variant could be potentially used as an additional marker for selecting patients that might require more intensive treatment (27). In Hodgkin's Lymphoma derived cell line, expressing Cao-CTAR2 variant of LAMPI showed weak expression of various cytokines, notably IFN- $\gamma$, and alteration in cell cycle. IFN- $\gamma$ has been shown to have anti-viral response against EBV, and its lowered expression might be the way through which Cao-CTAR2 infected cells escape the immune anti-viral surveillance and promote cancer (28). 


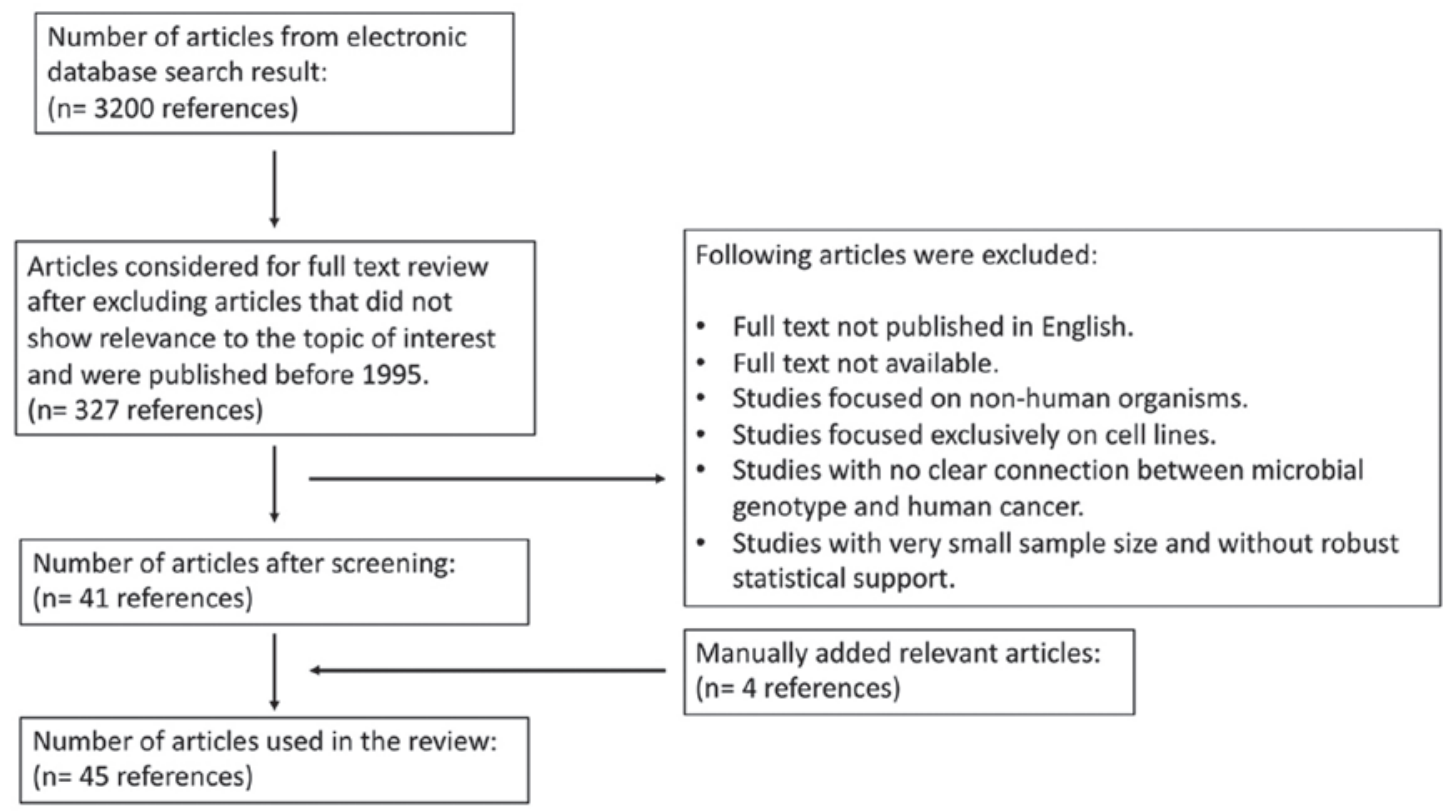

Figure 1. Workflow used to compile the 45 relevant articles for the present review.

Human herpes virus 8. HHV8 triggered AIDS-associated Kaposi's sarcoma (AIDS-KS) is the most severe and resistant form of KS tumor. One recent study aimed to investigate the association between HHV8 variability and development of AIDS-KS used fragments of ORF K1 for genotyping HHV8 virus (29). ORF K1 contains two highly variable regions, VR1 and VR2, that allow the identification of major genotypes of HHV8 and encode for a transmembrane molecule crucial for the HHV8 lifecycle and synergistically works with HIV-1 Tat to promote tumors. This study compared the variability in the ORF K1 of HHV8 in Brazilian individuals with and without KS. Among genotypes A, B, C and F, it was discovered that only genotype $\mathrm{B}$ showed predominance compared to other genotypes $(\mathrm{P}=0.0182$, Fisher's exact test) suggesting this genotype may be associated with better prognosis of $\mathrm{KS}$ tumor (29).

Human papillomavirus. HPV is linked to several cancers worldwide of which its association with cervical cancer is particularly noteworthy. Infection with HPV is linked to cervical cancers worldwide, and among all the described genotypes, $70 \%$ of all cervical cancers are linked to HPV-16 and 18 infection, although several other HPV types are also categorized under high risk (30). In a case control study of 264 invasive cervical cancer patients and 8,428 controls in Wales, it was discovered that there was a substantial high risk of cervical cancer in patients infected with HPV-16 $[\mathrm{OR}$ (adjusted for age) $=2770 ; 95 \% \mathrm{CI}, 1050-7320]$ and HPV-18 [OR (adjusted for age) $=950 ; 95 \%$ CI, 330-2740]. In addition to HPV types 16 and 18 several other HPV types $(31,33,35,39,45,52,56,58,59,66)$ were also linked to an increased risk for cervical cancer [OR (adjusted for age) between 20.2 to 386] (31). In addition, HPV is also associated with various noncervical cancers, and strikingly HPV-16 and 18 are again shown to be linked with $90 \%$ of these HPV related non-cervical cancers (7). In a case control study, it was found that HPV-16 infection increased the odds of oropharyngeal cancer by 14 -fold $(\mathrm{OR}=14.6$, 95\% CI: 6.3-36.6) (32). Another study that was performed to determine whether HPV genotypes were associated with anal pathology in HIV-infected males with a history of anal-receptive intercourse; it was discovered that HPV types16 (38\%), $18(19 \%), 45(22 \%)$, and $52(19 \%)$ were the most common types found in patients, and there was an increased odds of prevalence of high-grade intra-anal disease (which is an anal cancer precursor) when infected with HPV-16 (OR=2.58, 95\% CI: 1.31-5.08, $\mathrm{P}=0.006)$ and HPV-31 (OR=4.74, 95\% CI: 2.00-11.22, P=0.0004) (33). This evidence demonstrates the importance of discriminating HPV types in order to determine the extent of associated risk for development of various cancers.

Hepatitis $C$ and $B$ viruses. Hepatocellular carcinoma (HCC) is the most common type of liver cancer and also the most frequent cause of deaths in patients with compensated cirrhosis; its prevalence has been linked to infection with hepatitis $\mathrm{C}$ virus (HCV) (34). In a prospective study of 163 consecutive $\mathrm{HCV}$-infected patients with cirrhosis, two genotypes were observed to be predominant; $64 \%$ of the patients were infected with genotype $1 \mathrm{~b}$ and $32 \%$ of the patients were infected with genotype $2 \mathrm{a} / \mathrm{c}$. After a median follow-up of 10.7 years (range $=0.6-17.22$ years), it was observed that the cumulative incidence of HCC was significantly higher $(\mathrm{P}=0.0001)$ and mortality after $\mathrm{HCV}$ infection was significantly greater $(\mathrm{P}<0.00001)$ in patients infected with genotype $1 \mathrm{~b}$ compared to genotype $2 \mathrm{a} / \mathrm{c}$. In fact patients infected with genotype $1 \mathrm{~b} \mathrm{HCV}$ carried a greater than three-fold risk factor of developing $\mathrm{HCC}$ compared to patients infected with genotype $2 \mathrm{a} / \mathrm{c}(\mathrm{HR}=3.02$, 95\% CI: 1.4-6.53) demonstrating that patients infected with genotype $1 \mathrm{~b}$ have substantial high risk of developing HCC compared to patients infected with genotype $2 \mathrm{a} / \mathrm{c}$ (35). In $\mathrm{HCV}$, variations in the $5^{\prime}$ untranslated region (UTR) region, instead of coding regions, was used to determine the viral genotypes (35). 


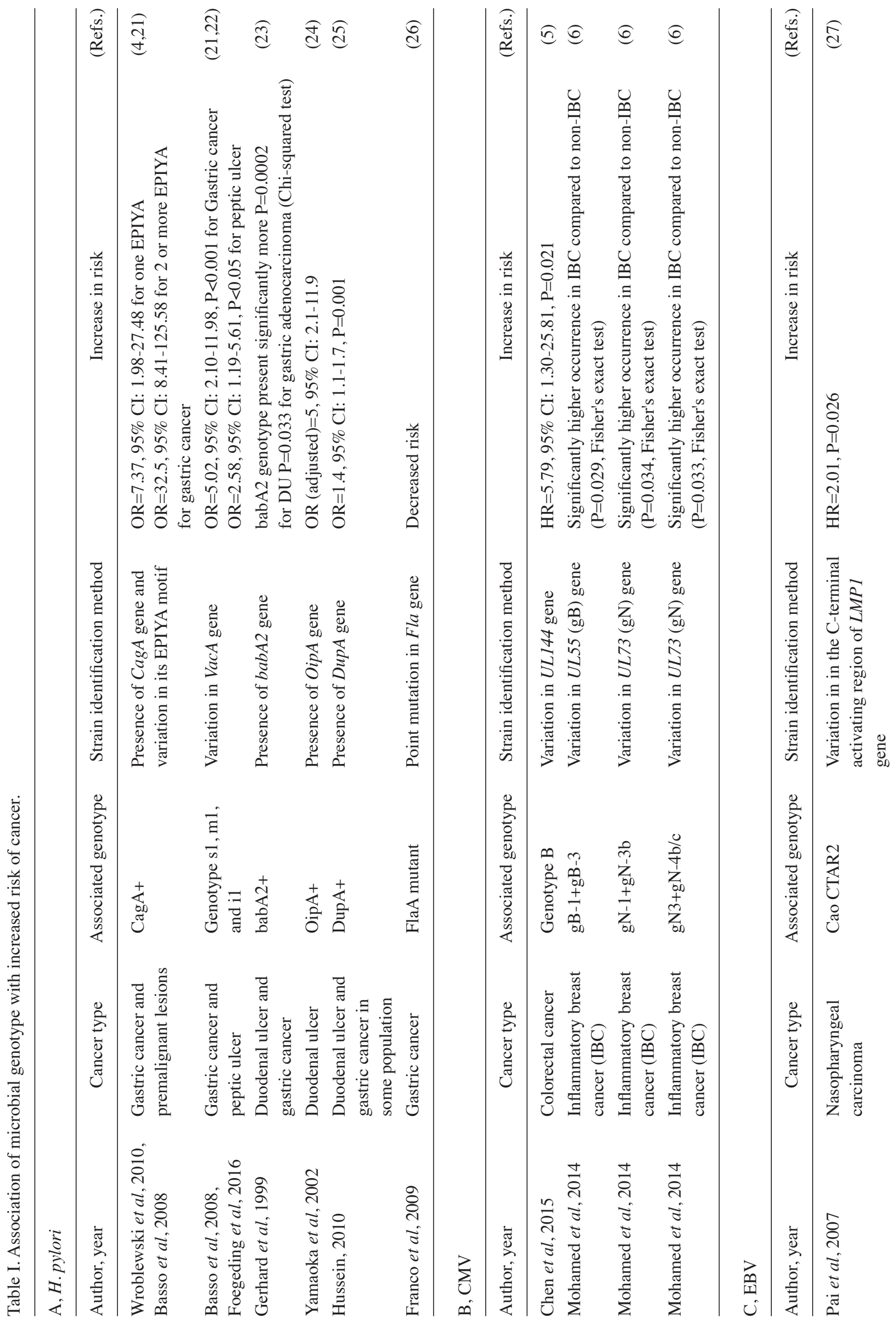




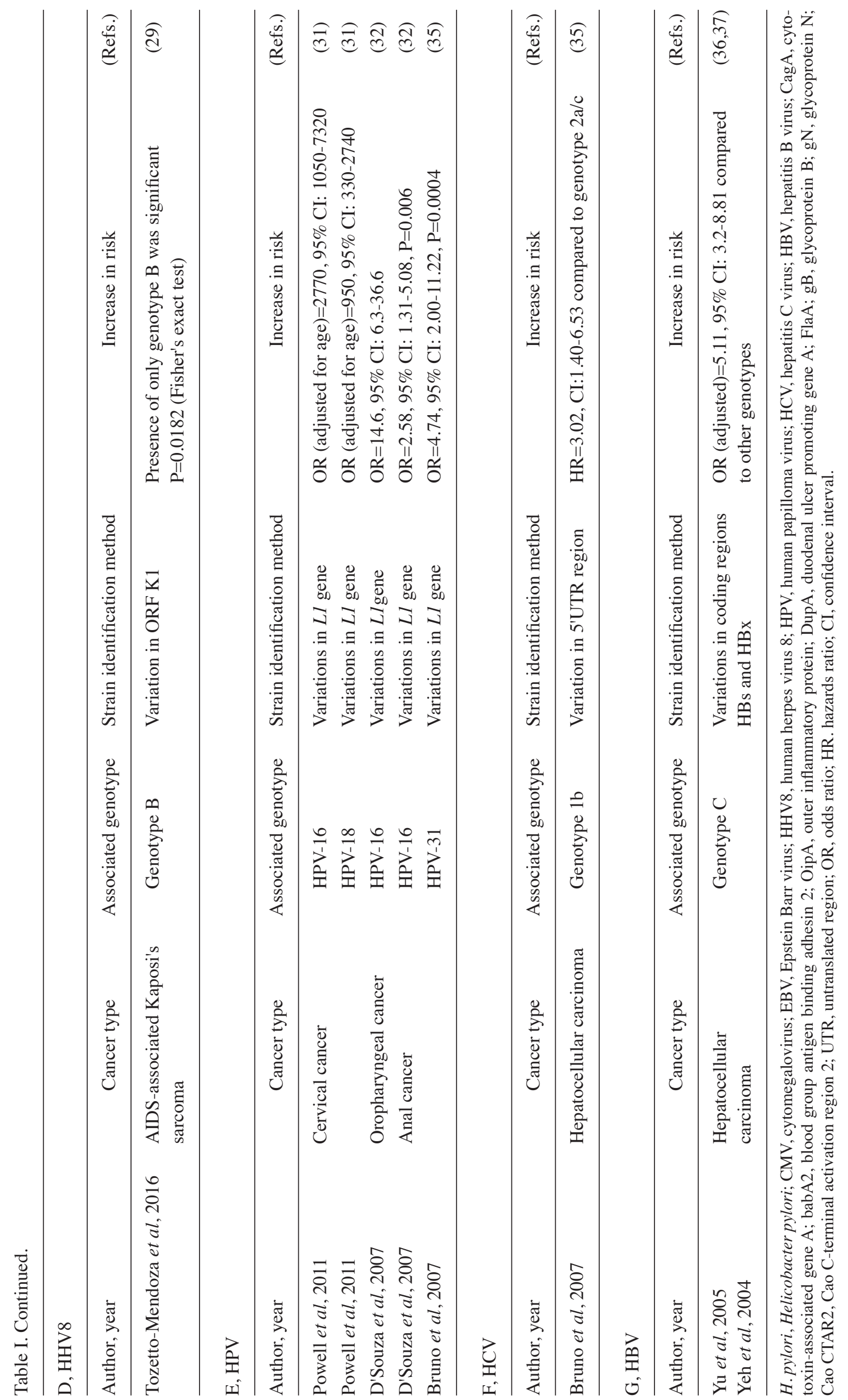


Hepatitis B virus (HBV) infection with circulating HBV surface antigenemia is associated with a 20 -fold increased risk of development of HCC relative to that in the absence of antigenemia. In a study conducted in Taiwanese men over 30 years of age, it was observed that HBV genotype $\mathrm{C}$ was associated with an increased risk of HCC compared with other HBV genotypes (adjusted OR=5.11, 95\% CI: 3.2-8.81) suggesting that patients infected with $\mathrm{HBV}$ genotype $\mathrm{C}$ were five times more likely to develop HCC compared to infection with other genotypes. Furthermore, both viral load and the presence of genotype $\mathrm{C}$ showed an additive effect and patients infected with this genotype with high viral load had up to 26.6-fold risk of developing HCC compared to patients infected with other genotypes and low viral load, showing that HBV mediated $\mathrm{HCC}$ is dependent on the viral genotype and also the viral load (36). Genotyping and quantification of HBV in this study was done utilizing the variations in the coding regions $\mathrm{HBs}$ and $\mathrm{HBx}$ in a single reaction using real-time PCR and melting curve analysis (37).

Human cytomegalovirus. In a study investigating genetic polymorphisms in human cytomegalovirus (HCMV) and its correlation with clinical outcomes in patients with colorectal cancer (CRC) the HCMV Genotype B was associated with shorter disease-free survival (DFS) and presence of this genotype was independently able to predict the recurrence of tumor in patients $(\mathrm{HR}=5.79,95 \% \mathrm{CI}: 1.30-25.81, \mathrm{P}=0.021)(5)$. Furthermore, the gene UL144 was most frequently expressed in samples with the genotype $B$ infection compared to infection with other genotypes. Because UL144 has been shown to have role in the host immune response, the authors speculate that UL144 may play an immunomodulatory role in the tumor microenvironment of CRC (5). In addition to a specific genotype of HCMV contributing towards a higher risk of CRC, the presence of mixed HCMV genotypes has been described to have a higher risk of developing inflammatory breast cancer (IBC). IBC is known to be a highly metastatic, aggressive and fatal form of breast cancer. In a study aimed to establish incidence and type of HCMV genotypes present in carcinoma tissues between HCMV infected IBC and non IBC patients, Intermediate Early (IE) gene was used to detect the presence of HCMV DNA and variation in genes UL55 $(\mathrm{gB})$ and $U L 73(\mathrm{gN})$ were used to determine the viral genotypes (6). Among the various genotypes and combination of genotypes tested in this study, IBC patients had a significantly higher prevalence of mixed genotypes: $g B-1+g B-3(P=0.029$, Fisher's exact test), $g N-1+g N-3 b(P=0.034$, Fisher's exact test), and $\mathrm{gN}-3+\mathrm{gN}-4 \mathrm{~b} / \mathrm{c}(\mathrm{P}=0.033$, Fisher's exact test $)$ compared to non-IBC patients. Additionally, the presence of mixed HCMV genotypes in IBC patients significantly correlated with lymphovascular invasion and formation of dermal lymphatic emboli which was not observed in patients without IBC (6). Together, these findings revealed that the prevalence of mixed HCMV genotypes might be an important factor in driving the progression of IBC.

\section{Interaction between human and microbe genetic factors}

In addition to the microbial genotype, the human genotype also plays an important role in determining cancer risk factors $(4,14)$. Interestingly there have been several reports of a synergistic interaction between host and microbial genetic factors leading to differential risk of developing cancer. Patients harboring susceptible variants of interleukin-1 $\beta$ (IL-1B) infected with more virulent strain of $H$. pylori were shown to have up to 87-fold higher risk of developing GC compared to baseline (Table II) (38). Another independent study showed that the prevalence of individuals with specific variations in IL-1B and IL-1 receptor antagonist (IL-1RN) when infected with strains positive for $\operatorname{Cag} A$ and harboring virulent versions of $\operatorname{VacA}$ showed an increased risk of developing severe histological alterations that precede gastric cancer including intestinal metaplasia, atrophic gastritis, severe lymphocytic infiltration, and severe granulocytic infiltration compared to individuals only harboring susceptible IL-1B and IL-1RN alleles (Table II) (39). Together these studies show that there is an interaction between human and microbial genotype that could result in an even more heightened cancer risk, and the ability to detect these variations would provide crucial information to more precisely predict cancer risks associated with bacterial infections.

As previously described, HPV is associated with the majority of cervical cancers with HPV 16 being the predominant factor in most cervical cancers. Interestingly, several studies have provided support that interaction between various human leukocyte antigen (HLA) alleles and HPV 16 subtypes may contribute towards differential risk factor for cervical cancer. A study in Swedish women showed that polymorphisms in HLA class I antigens HLA-B*44, HLA-B*51, or HLA-B*57 had approximately 4-5-fold increase in risk for cervical cancer in presence of a $\mathrm{L} 83 \mathrm{~V}$ variant in E6 gene of HPV-16 (Table II) $(40,41)$. Interestingly it was discovered that HLA-B*15 allele was completely absent in Swedish women with cervical cancer which was also observed in studies conducted in a German and Italian cohort. Although this study consisted of a rather small sample size $(n=27)$, the authors speculate that the HLA-B*15 allele may contribute to an effective immune response against HPV-16 infection (40). Another study in Chinese women showed that polymorphisms in HLA class II alleles had differential risk for cervical cancer in presence of two HPV 16 variants. There was a higher risk factor associated with DQB1*060101 allele, and a lower risk factor associated with DRB1*150101-DQB1*0602 and DRB1*070101-DQB1*0201 alleles in individuals infected with HPV-16 As variant (Table II) (42). Additionally, women with HLA types DQB1*060101, DQB1*030201, and DPB1*1301 had a higher risk of cervical cancer, while HLA type DRB1-DQB1 showed no significant risk when infected with HPV-16 E6 prototype-positive variant (Table II) (42). Together these studies demonstrate that certain combinations of HLA types and HPV 16 types may be crucial factors in determining oncogenicity, further supporting the importance of understanding human-microbe genetic interactions for improved cancer diagnosis and prognosis.

\section{Conclusion and prospects}

There is overwhelming evidence that microbial genotype information is crucial for determining cancer risks in patients with microbial infection. This observation provides, at a 
Table II. Differences in cancer risks as a result of interaction between microbe and host genetic factors.

\begin{tabular}{|c|c|c|c|c|c|}
\hline Author, year & Cancer type & Microbe genopype & Human genotype & Odds ratio & (Refs.) \\
\hline \multirow{10}{*}{$\begin{array}{l}\text { Figueiredo } \\
\text { et al, } 2002\end{array}$} & Gastric cancer & VacA s 1 & -- & $\mathrm{OR}=17,95 \% \mathrm{CI}: 7.8-38$ & $(38)$ \\
\hline & Gastric cancer & VacA m1 & -- & $\mathrm{OR}=6.7,95 \% \mathrm{CI}: 3.6-12$ & \\
\hline & Gastric cancer & CagA & -- & $\mathrm{OR}=15,95 \%$ CI: $7.4-29$ & \\
\hline & Gastric cancer & - & IL-1B-511*T & $\mathrm{OR}=3.3,95 \% \mathrm{CI}: 1.3-8.2$ & \\
\hline & Gastric cancer & VacA s 1 & IL-1B-511*T & $\mathrm{OR}=87,95 \%$ CI: $11-679$ & \\
\hline & Gastric cancer & VacA m1 & IL-1B-511*T & $\mathrm{OR}=7.4,95 \%$ CI: 3.2-17 & \\
\hline & Gastric cancer & CagA & IL-1B-511*T & $\mathrm{OR}=25,95 \%$ CI: $8.2-77$ & \\
\hline & Gastric cancer & VacA s 1 & IL-1RN*2 & $\mathrm{OR}=32,95 \%$ CI: $7.8-134$ & \\
\hline & Gastric cancer & VacA m1 & IL-1RN*2 & $\mathrm{OR}=8.8,95 \%$ CI: $2.2-35$ & \\
\hline & Gastric cancer & CagA & IL-1RN*2 & $\mathrm{OR}=23,95 \% \mathrm{CI}: 7-7.2$ & \\
\hline \multirow[t]{8}{*}{ Rad et al, 2003} & $\begin{array}{l}\text { Severe lymphocytic } \\
\text { infiltration }\end{array}$ & - & $\begin{array}{l}\text { IL-1B-511*T } \\
\text { IL-1RN*2 }\end{array}$ & $\mathrm{OR}=2.6,95 \% \mathrm{CI}: 1.3-5.7$ & (39) \\
\hline & $\begin{array}{l}\text { Severe granulocytic } \\
\text { infiltration }\end{array}$ & - & $\begin{array}{l}\text { IL-1B-511*T } \\
\text { IL-1RN*2 }\end{array}$ & $\mathrm{OR}=2.7,95 \%$ CI: $1.3-5.7$ & \\
\hline & Intestinal metaplasia & - & $\begin{array}{l}\text { IL-1B-511*T } \\
\text { IL-1RN*2 }\end{array}$ & $\mathrm{OR}=2.3,95 \%$ CI: $1.2-4.6$ & \\
\hline & Atrophic gastritis & - & $\begin{array}{l}\mathrm{IL}-1 \mathrm{~B}-511 * \mathrm{~T} \\
\mathrm{IL}-1 \mathrm{RN} * 2\end{array}$ & $\mathrm{OR}=1.7,95 \% \mathrm{CI}: 0.8-3.4$ & \\
\hline & $\begin{array}{l}\text { Severe lymphocytic } \\
\text { infiltration }\end{array}$ & $\begin{array}{l}\text { CagA } \\
\text { VacA s1 }\end{array}$ & $\begin{array}{l}\text { IL-1B-511*T } \\
\text { IL-1RN*2 }\end{array}$ & $\mathrm{OR}=24.8,95 \%$ CI: 5.2-117.3 & \\
\hline & $\begin{array}{l}\text { Severe granulocytic } \\
\text { infiltration }\end{array}$ & $\begin{array}{l}\text { CagA } \\
\text { VacA s1 }\end{array}$ & $\begin{array}{l}\text { IL-1B-511*T } \\
\text { IL-1RN*2 }\end{array}$ & OR=9.5, 95\% CI: $2.8-32.1$ & \\
\hline & Intestinal metaplasia & $\begin{array}{l}\text { CagA } \\
\text { VacA s1 }\end{array}$ & $\begin{array}{l}\text { IL-1B-511*T } 2 \\
\text { IL-1RN* }\end{array}$ & $\mathrm{OR}=6.0,95 \%$ CI: $2.4-15.5$ & \\
\hline & Atrophic gastritis & $\begin{array}{l}\text { CagA } \\
\text { VacA s } 1\end{array}$ & $\begin{array}{l}\mathrm{IL}-1 \mathrm{~B}-511 * \mathrm{~T} \\
\mathrm{IL}-1 \mathrm{RN} * 2\end{array}$ & $\mathrm{OR}=2.4,95 \%$ CI: $0.93-6.2$ & \\
\hline
\end{tabular}

$\mathrm{B}, \mathrm{HPV}$

\begin{tabular}{|c|c|c|c|c|c|}
\hline Author, year & Cancer type & Microbe genopype & Human genotype & Odds ratio & (Refs.) \\
\hline \multirow[t]{3}{*}{ Zehbe et al, 2003} & Cervical cancer & HPV-16 E6 L83V & HLA-B*44 & $\mathrm{OR}=3.5,95 \% \mathrm{CI}: 1.1-11.1$ & $(40)$ \\
\hline & Cervical cancer & HPV-16 E6 L83V & HLA-B*51 & $\mathrm{OR}=4.2,95 \%$ CI: $1.19-14.69$ & \\
\hline & Cervical cancer & HPV-16 E6 L83V & HLA-B*57 & $\mathrm{OR}=4.67,95 \% \mathrm{CI}: 1.2-18.6$ & \\
\hline \multirow[t]{7}{*}{ Wu et al, 2007} & Cervical cancer & HPV-16 As & DQB1*060101 & $\mathrm{OR}=4.47,95 \%$ CI: $2.16-9.27$ & $(42)$ \\
\hline & Cervical cancer & HPV-16 As & $\begin{array}{l}\text { DRB } 1 * 150101- \\
\text { DQB } 1 * 0602\end{array}$ & $\mathrm{OR}=0.31,95 \% \mathrm{CI}: 0.09-1.08$ & \\
\hline & Cervical cancer & HPV-16 As & $\begin{array}{l}\text { DRB } 1 * 070101- \\
\text { DQB } 1 * 0201\end{array}$ & $\mathrm{OR}=0.16,95 \% \mathrm{CI}: 0.02-1.26$ & \\
\hline & Cervical cancer & $\begin{array}{l}\text { HPV-16 E6 } \\
\text { prototype-positive }\end{array}$ & DQB1*060101 & $\mathrm{OR}=5.95,95 \% \mathrm{CI}: 2.16-9.27$ & \\
\hline & Cervical cancer & $\begin{array}{l}\text { HPV-16 E6 } \\
\text { prototype-positive }\end{array}$ & DQB1*030201 & $\mathrm{OR}=10.87,95 \%$ CI: $3.16-37.48$ & \\
\hline & Cervical cancer & $\begin{array}{l}\text { HPV-16 E6 } \\
\text { prototype-positive }\end{array}$ & DPB1*1301 & $\mathrm{OR}=7.40,95 \% \mathrm{CI}: 2.18-25.17$ & \\
\hline & Cervical cancer & $\begin{array}{l}\text { HPV-16 E6 } \\
\text { prototype-positive }\end{array}$ & DRB1-DQB1 & No significant effect & \\
\hline
\end{tabular}

IL-1B-511*T, polymorphic allele with $\mathrm{T}$ instead of $\mathrm{C}$ at position 511 of the regulatory region of IL-1B gene; IL-1RN*2, homozygote for two tandem repeat allele in the intron 2 of IL-1RN gene; -, Absence of virulent H. pylori strain; --, absence of IL-1B-511*T and IL-1RN*2; OR, odds ratio; CI, confidence interval; IL, interleukin; HLA, human leukocyte antigen. 


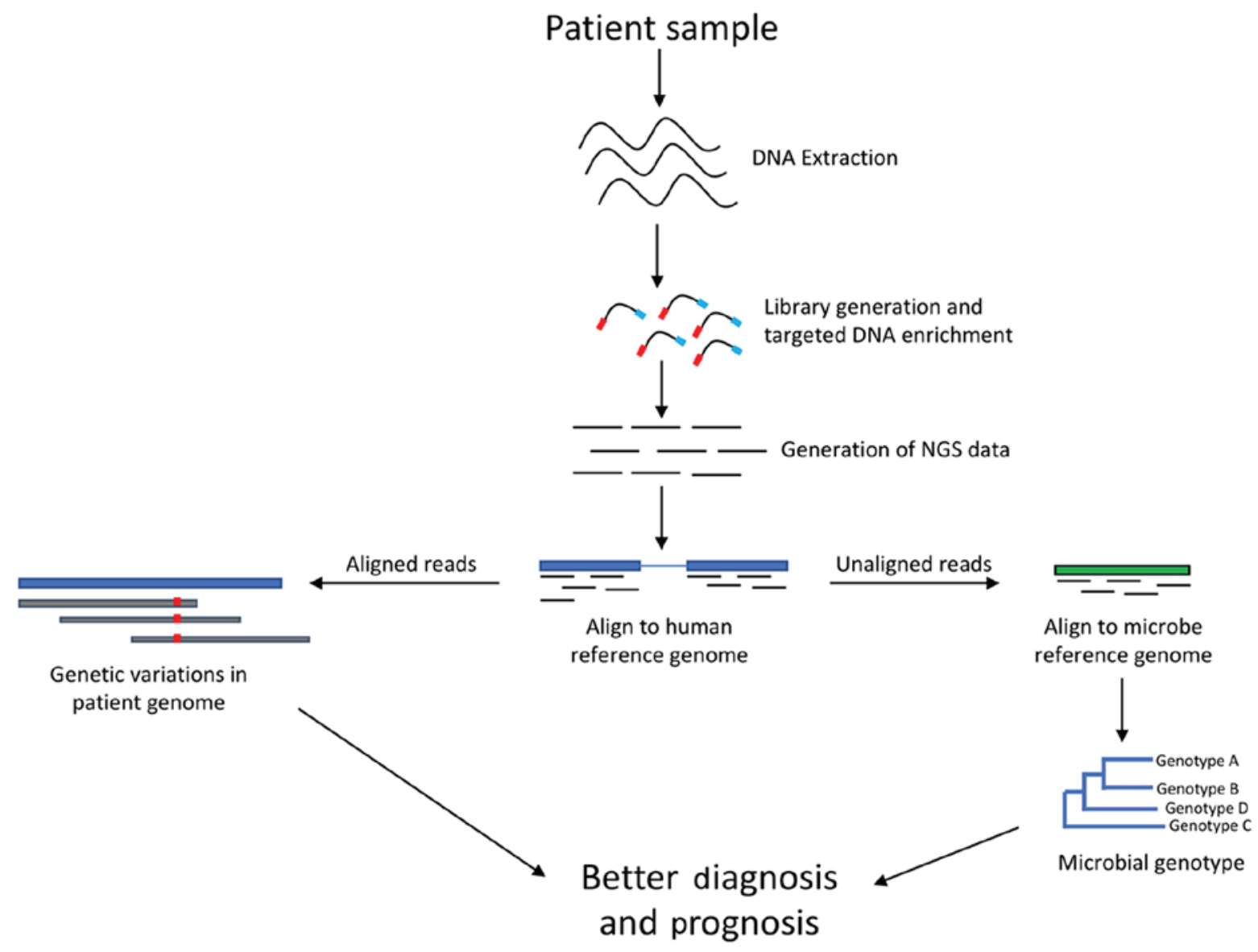

Figure 2. Workflow for the analysis of microbiologic organisms. DNA from the patient is extracted and a library is prepared. At this step, informative targeted patient and microbial DNA are enriched. Deep sequencing of the library is then performed using next generation sequencing. The generated reads are aligned to a human reference genome and the mapped reads are used to detect genetic variations in the patient. The reads that do not map to the human reference are mapped to microbial reference genomes and are used for the detection and retrieval of genotype information of microbial infections. Together with the genetic variation information from patients and microbes, better diagnosis and prognosis can be accomplished during downstream interpretation. NGS, next generation sequencing.

minimum, a partial explanation for the disparity between the high prevalence of infection with some malignancy-associated pathogens in human populations and the fact that only some of those infected develop malignancies. Several clinical assays that are currently in use detect microbes only at the species level, which makes it often difficult to accurately predict the associated risks. Incorporation of the genotype information into clinical assays would provide a further step in assessing risk factors associated with specific strains and has the potential to greatly enhance cancer diagnosis and prognosis. Such information could also greatly enhance treatment decisions. For example, patients infected with high risk genotypes at diagnosis could be considered for different and more intensive therapy than patients infected with intermediate or low risk genotypes. In addition, individuals infected with high risk genotypes could be targeted with antimicrobial treatment in order to prevent the development of malignancy.

With the advent of novel sequencing technologies that are able to generate massive amount of sequence data in parallel, and using ever improving state of the art bioinformatic pipelines, we have the power to detect not only the variations in the human genome but also robustly detect variations in the microbial genomes within an individual (43). Leveraging information described in the literature, combined with the cutting-edge sequencing technology and its analysis, data from informative genomic sites can be used to greatly improve prediction of cancer risks associated with microbial infections potentially also aiding in cancer treatment. In fact, various research groups have already started implementing this technology to detect virulent strains of microbes present in patient samples. An NGS based analysis was used to detect variation in $\mathrm{CagA}$ and $\mathrm{VacA}$ genes in $H$. pylori and discriminate between variants associated with GC and MALT lymphoma (44). Further, metagenomics approaches have been also used to characterize highly virulent bacterial strains (45). Moving forward, studies conducted using approaches such as shotgun metagenomics could further provide with better microbial genomic markers associated with high risk of cancer. Our lab has recently developed a targeted NGS panel called that targets not only important human genomic sites but also regions in the microbial genome (Fig. 2). Thus, this panel is not only able to provide information on genetic variations in patients, but also can be used for detection of variations present in targeted microbial sequences. Such panels can be employed into clinical assays to target informative sites in the microbes of interest and retrieve genotype information without having to perform whole genome sequencing, which is rather expensive and time consuming. Additionally, interactions between microbe and human genetic factors has also been shown to influence 
cancer risks in patients, where specific genotype combinations between humans and microbes can lead to further heightened or differential risk of cancer (Table II). Targeted human and microbial panels could be utilized in clinical assays to generate invaluable data in a single workflow to detect the prevalence of these high-risk human-microbe genotype combinations in patients.

Microbial intervention leading to cancer has been very well established, however not all infections lead to cancer development. Microbial genotype is one of the crucial factors that dictates the risk factors associated with these infections. With the power of sequencing technologies and our understanding of the human and microbial genomes, we can now begin to fine tune clinical assays that could provide a much better understanding of cancer risk associated with microbial infections. Such assays could also potentially lead to interventions to prevent the development of malignancy and direct their therapy when present.

\section{Acknowledgements}

Not applicable.

\section{Funding}

No funding was received.

\section{Availability of data and materials}

The datasets used and/or analyzed during the current study are available from the corresponding author on reasonable request.

\section{Authors' contributions}

DJ and RSO designed the current study, wrote the manuscript and analyzed the data. AB, DJ, SD, KS, and NB edited the manuscript and analyzed the data. All authors read and approved the final manuscript.

\section{Ethics approval and consent to participate}

Not applicable.

\section{Patient consent for publication}

Not applicable.

\section{Competing interests}

The authors declare that they have no competing interests.

\section{References}

1. Dzutsev A, Badger JH, Perez-Chanona E, Roy S, Salcedo R, Smith CK and Trinchieri G: Microbes and cancer. Annu Rev Immunol 35: 199-228, 2017.

2. Hudnall SD (ed): Viruses and Human Cancer. Springer-Verlag, New York, NY, 2014.

3. Mager DL: Bacteria and cancer: Cause, coincidence or cure? A review. J Transl Med 4: 14, 2006.

4. Wroblewski LE, Peek RM Jr and Wilson KT: Helicobacter pylori and gastric cancer: Factors that modulate disease risk Clin Microbiol Rev 23: 713-739, 2010.
5. Chen HP, Jiang JK, Chan CH, Teo WH, Yang CY, Chen YC, Chou TY, Lin CH and Chan YJ: Genetic polymorphisms of the human cytomegalovirus UL144 gene in colorectal cancer and its association with clinical outcome. J Gen Virol 96: 3613-3623, 2015.

6. Mohamed HT, El-Shinawi M, Nouh MA, Bashtar AR, Elsayed ET, Schneider RJ and Mohamed MM: Inflammatory breast cancer: High incidence of detection of mixed human cytomegalovirus genotypes associated with disease pathogenesis. Front Oncol 4: 246, 2014.

7. Lowy DR and Schiller JT: Reducing HPV-associated cancer globally. Cancer Prev Res (Phila) 5: 18-23, 2012.

8. Poiesz BJ, Ruscetti FW, Gazdar AF, Bunn PA, Minna JD and Gallo RC: Detection and isolation of type $\mathrm{C}$ retrovirus particles from fresh and cultured lymphocytes of a patient with cutaneous T-cell lymphoma. Proc Natl Acad Sci USA 77: 7415-7419, 1980.

9. Chadburn A, Said J, Gratzinger D, Chan JK, de Jong D, Jaffe ES, Natkunam Y and Goodlad JR: HHV8/KSHV-positive lymphoproliferative disorders and the spectrum of plasmablastic and plasma cell neoplasms: 2015 SH/EAHP Workshop Report-Part 3. Am J Clin Pathol 147: 171-187, 2017.

10. Nagy A, Bhaduri A, Shahmarvand N, Shahryari J, Zehnder JL, Warnke RA, Mughal T, Ali S and Ohgami RS: Next-generation sequencing of idiopathic multicentric and unicentric Castleman disease and follicular dendritic cell sarcomas. Blood Adv 2: 481-491, 2018.

11. Farrell PJ: Epstein-barr virus and cancer. Annu Rev Pathol 14: 29-53, 2019.

12. Hoffmann JC, Chisholm KM, Cherry A, Chen J, Arber DA, Natkunam Y, Warnke RA and Ohgami RS: An analysis of MYC and EBV in diffuse large B-cell lymphomas associated with angioimmunoblastic T-cell lymphoma and peripheral T-cell lymphoma not otherwise specified. Hum Pathol 48: 9-17, 2016.

13. Uemura N, Okamoto S, Yamamoto S, Matsumura $\mathrm{N}$ Yamaguchi S, Yamakido M, Taniyama K, Sasaki N and Schlemper RJ: Helicobacter pylori infection and the development of gastric cancer. N Engl J Med 345: 784-789, 2001.

14. Talledo M, López G, Huyghe JR, Verdonck K, González E, Clark D, Vanham G, Gotuzzo E, Van Camp G and Van Laer L: Possible implication of NFKB1A and NKG2D genes in susceptibility to HTLV-1-associated myelopathy/tropical spastic paraparesis in Peruvian patients infected with HTLV-1. J Med Virol 84: 319-326, 2012.

15. Edwards RH, Sitki-Green D, Moore DT and Raab-Traub N: Potential selection of LMP1 variants in nasopharyngeal carcinoma. J Virol 78: 868-881, 2004.

16. Michaelis M, Doerr HW and Cinatl J: The story of human cytomegalovirus and cancer: Increasing evidence and open questions. Neoplasia 11: 1-9, 2015.

17. Parsa N: Environmental factors inducing human cancers. Iran J Public Health 41: 1-9, 2012

18. Muenst S, Läubli H, Soysal SD, Zippelius A, Tzankov A and Hoeller S: The immune system and cancer evasion strategies: Therapeutic concepts. J Intern Med 279: 541-562, 2016.

19. Chen JN, Ding YG, Feng ZY, Li HG, He D, Du H, Wu B and Shao CK: Association of distinctive Epstein-Barr virus variants with gastric carcinoma in Guangzhou, southern China. J Med Virol 82: 658-667, 2010.

20. Hatakeyama M: Helicobacter pylori CagA and gastric cancer: A paradigm for hit-and-run carcinogenesis. Cell Host Microbe 15: 306-316, 2014.

21. Basso D, Zambon CF, Letley DP, Stranges A, Marchet A, Rhead JL, Schiavon S, Guariso G, Ceroti M, Nitti D, et al: Clinical relevance of Helicobacter pylori cag A and vacA gene polymorphisms. Gastroenterology 135: 91-99, 2008.

22. Foegeding NJ, Caston RR, McClain MS, Ohi MD and Cover TL: An overview of Helicobacter pylori VacA toxin biology. Toxins (Basel) 8: E173, 2016.

23. Gerhard M, Lehn N, Neumayer N, Borén T, Rad R, Schepp W, Miehlke S, Classen M and Prinz C: Clinical relevance of the Helicobacter pylori gene for blood-group antigen-binding adhesin. Proc Natl Acad Sci USA 96: 12778-12783, 1999.

24. Yamaoka Y, Kikuchi S, el-Zimaity HMT, Gutierrez O, Osato MS and Graham DY: Importance of Helicobacter pylori oipA in clinical presentation, gastric inflammation, and mucosal interleukin 8 production. Gastroenterology 123: 414-424, 2002.

25. Hussein NR: The association of dupA and Helicobacter pylori-related gastroduodenal diseases. Eur J Clin Microbiol Infect Dis 29: 817-821, 2010.

26. Franco AT, Friedman DB, Nagy TA, Romero-Gallo J, Krishna U, Kendall A, Israel DA, Tegtmeyer N, Washington MK and Peek RM Jr: Delineation of a carcinogenic Helicobacter pylori proteome. Mol Cell Proteomics 8: 1947-1958, 2009. 
27. Pai PC, Tseng CK, Chuang CC, Wei KC, Hao SP, Hsueh C, Chang KP and Tsang NM: Polymorphism of C-terminal activation region 2 of Epstein-Barr virus latent membrane protein 1 in predicting distant failure and post-metastatic survival in patients with nasopharyngeal carcinoma. Head Neck 29: 109-119, 2007.

28. Sueur C, Lupo J, Mas P, Morand P and Boyer V: Difference in cytokine production and cell cycle progression induced by Epstein-Barr virus Lmp1 deletion variants in Kmh2, a Hodgkin lymphoma cell line. Virol J 11: 94, 2014.

29. Tozetto-Mendoza TR, Ibrahim KY, Tateno AF, Oliveira CM, Sumita LM, Sanchez MC, Luna EJ, Pierrotti LC, Drexler JF, Braz-Silva PH, et al: Genotypic distribution of HHV-8 in AIDS individuals without and with Kaposi sarcoma: Is genotype $\mathrm{B}$ associated with better prognosis of AIDS-KS? Medicine (Baltimore) 95: e5291, 2016.

30. de Martel C, Plummer M, Vignat J and Franceschi S: Worldwide burden of cancer attributable to HPV by site, country and HPV type. Int J Cancer 141: 664-670, 2017.

31. Powell NG, Hibbitts SJ, Boyde AM, Newcombe RG, Tristram AJ and Fiander AN: The risk of cervical cancer associated with specific types of human papillomavirus: A case-control study in a UK population. Int J Cancer 128: 1676-1682, 2011.

32. D'Souza G, Kreimer AR, Viscidi R, Pawlita M, Fakhry C, Koch WM, Westra WH and Gillison ML: Case-control study of human papillomavirus and oropharyngeal cancer. N Engl J Med 356: 1944-1956, 2007.

33. Salit IE, Tinmouth J, Chong S, Raboud J, Diong C, Su D, Sano M, Lytwyn A, Chapman W and Mahony J: Screening for HIV-associated anal cancer: Correlation of HPV genotypes, p16, and E6 transcripts with anal pathology. Cancer Epidemiol Biomarkers Prev 18: 1986-1992, 2009.

34. Benvegnù L, Gios M, Boccato $S$ and Alberti $A$ : Natural history of compensated viral cirrhosis: A prospective study on the incidence and hierarchy of major complications. Gut 53: 744-749, 2004.

35. Bruno S, Crosignani A, Maisonneuve P, Rossi S, Silini E and Mondelli MU: Hepatitis $C$ virus genotype $1 b$ as a major risk factor associated with hepatocellular carcinoma in patients with cirrhosis: A seventeen-year prospective cohort study. Hepatology 46: 1350-1356, 2007.

36. Yu MW, Yeh SH, Chen PJ, Liaw YF, Lin CL, Liu CJ, Shih WL, Kao JH, Chen DS and Chen CJ: Hepatitis B virus genotype and DNA level and hepatocellular carcinoma: A prospective study in men. J Natl Cancer Inst 97: 265-272, 2005.

37. Yeh SH, Tsai CY, Kao JH, Liu CJ, Kuo TJ, Lin MW, Huang WL, Lu SF, Jih J, Chen DS and Chen PJ: Quantification and genotyping of hepatitis B virus in a single reaction by real-time PCR and melting curve analysis. J Hepatol 41: 659-666, 2004.

38. Figueiredo C, Machado JC, Pharoah P, Seruca R, Sousa S, Carvalho R, Capelinha AF, Quint W, Caldas C, van Doorn LJ, et al: Helicobacter pylori and interleukin 1 genotyping: An opportunity to identify high-risk individuals for gastric carcinoma. J Natl Cancer Inst 94: 1680-1687, 2002.
39. Rad R, Prinz C, Neu B, Neuhofer M, Zeitner M, Voland P, Becker I, Schepp W and Gerhard M: Synergistic effect of Helicobacter pylori virulence factors and interleukin-1 polymorphisms for the development of severe histological changes in the gastric mucosa. J Infect Dis 188: 272-281, 2003.

40. Zehbe I, Mytilineos J, Wikström I, Henriksen R, Edler L and Tommasino M: Association between human papillomavirus 16 E6 variants and human leukocyte antigen class I polymorphism in cervical cancer of Swedish women. Hum Immunol 64: 538-542, 2003.

41. Mirabello L, Clarke MA, Nelson CW, Dean M, Wentzensen N, Yeager M, Cullen M, Boland JF; NCI HPV Workshop, Schiffman M and Burk RD: The intersection of HPV epidemiology, genomics and mechanistic studies of HPV-mediated carcinogenesis. Viruses 10: E80, 2018.

42. Wu Y, Liu B, Lin W, Xu Y, Li L, Zhang Y, Chen S and Xu A: HPV-16 E6 variants and HLA class II polymorphism among Chinese women with cervical cancer. J Med Virol 79: 439-446, 2007.

43. Sridhar K, Singh A, Butzmann A, Jangam D and Ohgami RS: Molecular genetic testing methodologies in hematopoietic diseases: Current and future methods. Int J Lab Hematol 41 (Suppl 1): S102-S116, 2019.

44. Hashinaga M, Suzuki R, Akada J, Matsumoto T, Kido Y, Okimoto T, Kodama M, Murakami K and Yamaoka Y: Differences in amino acid frequency in CagA and VacA sequences of Helicobacter pylori distinguish gastric cancer from gastric MALT lymphoma. Gut Pathog 8: 54, 2016.

45. Deurenberg RH, Bathoorn E, Chlebowicz MA, Couto N, Ferdous M, García-Cobos S, Kooistra-Smid AM, Raangs EC, Rosema S, Veloo AC, et al: Application of next generation sequencing in clinical microbiology and infection prevention. J Biotechnol 243: 16-24, 2017.

This work is licensed under a Creative Commons Attribution-NonCommercial-NoDerivatives 4.0 International (CC BY-NC-ND 4.0) License. 